

EVOLUTION

\section{Red Queen forces extinctions}

Mammalian extinctions seem to be driven more by a failure to keep up with evolutionary pace than by random swings in diversity.

Tiago Quental at the University of Sao Paulo in Brazil and Charles Marshall at the University of California, Berkeley, analysed 19 mammalian clades groups of species descended from a common ancestor that had well-preserved fossil records and had either become extinct or declined in diversity within the past 66 million years.

Diversity loss was due to new lineages arising at lower rates and extinctions occurring at higher rates. The authors say clades' decline can be explained by the Red Queen hypothesis: that species must continue to evolve to keep pace with a deteriorating environment.

Science http://dx.doi.

org/10.1126/science.1239431

(2013)

PLANT SCIENCES

\section{Vegetables' daily rhythm}

Harvested vegetables are capable of the same daily cycles as the plants they come from.

Janet Braam at Rice University in Houston, Texas, and her colleagues set the

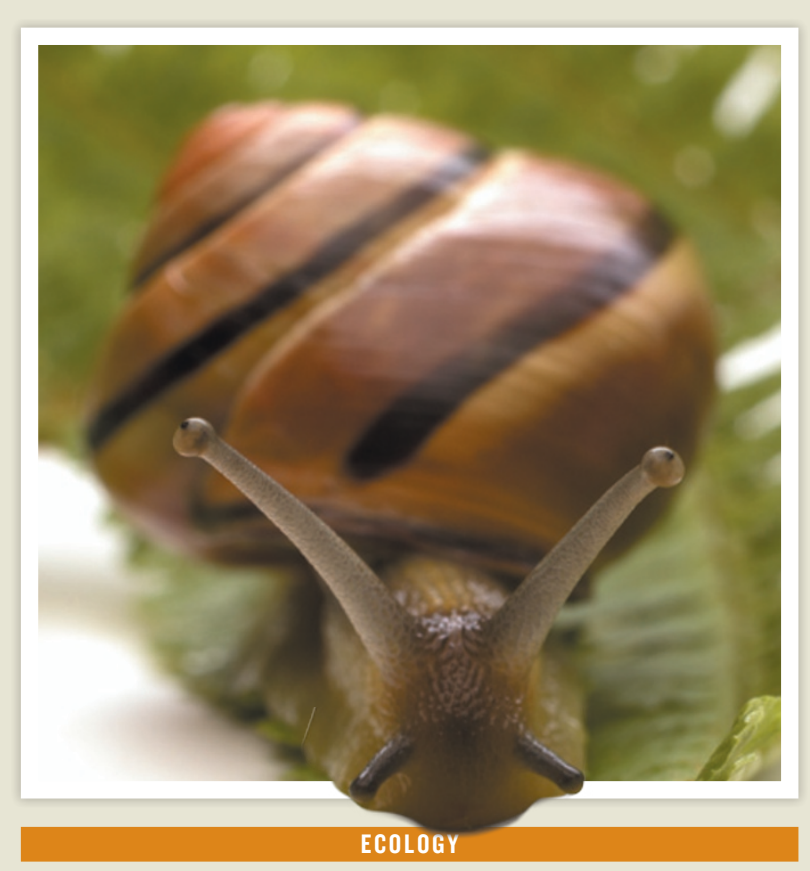

\section{Escargot on the go}

Ancient humans' taste for snails could explain an unusual pattern of present-day distribution for one snail species.

Adele Grindon and Angus Davison at the University of Nottingham, UK, sequenced a mitochondrial gene in 111 European populations of the land snail Cepaea nemoralis (pictured). Of the seven lineages that they identified, one was found just in Ireland and in a region of the Eastern Pyrenees in southwest Europe.

The oldest $C$. nemoralis fossils in Ireland date to about 8,000 years ago - around the time of the first human habitation of the island. The authors suggest that ancient humans might have carried the snails - a popular food with them as they moved between the Mediterranean and the Atlantic, following Europe's Garonne river.

If examples of other species are found in Ireland and the Iberian peninsula, but not between, this could confirm the migratory route.

PLoS ONE 8, e65792 (2013)

biological clock of shop-

bought cabbages (Brassica oleracea) by exposing them to daily light-dark cycles. The researchers found that the cabbage tissue accumulated chemical defences against herbivores during the light cycle. Intact Arabidopsis plants use the same cycle to guard against pests. When the daily rhythm of the cabbages was synced with that of the plantmunching larvae of the moth Trichoplusia ni (pictured), the vegetables were nibbled less than those whose rhythm was out of sync.

The protective cycling was reproduced in other harvested crops, including blueberries, sweet potatoes and carrots, suggesting that it could be a way to protect fruit and vegetables from pests. The researchers speculate that daily rhythms in harvested produce might also affect its nutrient value.

Curr. Biol. http://dx.doi. org/10.1016/j.cub.2013.05.034 (2013)

ARCHAEOLOGY

\section{Shells show rise of Homo sapiens}

The size of ancient limpet shells suggests that human populations began swelling around 50,000 years ago, long after key cultural innovations appear in the archaeological record.

Teresa Steele at the University of California, Davis, and Richard Klein at Stanford University, California, measured the size of limpet shells from archaeological sites in South Africa, inferring that smaller shells are linked to increased harvesting and therefore larger human settlements. Shells from the Middle Stone Age, 200,000 to 50,000 years ago, were consistently bigger than shells from Late Stone Age sites, suggesting that there was an increase in population growth in this later era.

Humans living on the coast of South Africa began creating symbolic artefacts, such as shell beads, around 100,000 years ago, when populations are thought to have been smaller. The researchers say their findings challenge the theory that such cultural behaviour was catalysed by high population densities that helped new innovations to spread.

\section{Proc. Natl Acad. Sci. USA} http://dx.doi.org/10.1073/ pnas.1304750110 (2013) 